\title{
Sustainable Cities through Urban Agriculture: Case of Developing Production and Socio-economic Environment within the Kurunegala Municipal Council Limits
}

\author{
Herath H.M.R.A. ${ }^{1}$, Jayasekara S.J.B.A. ${ }^{1}$, Debarawatta R.D.N. ${ }^{1}$, Jayasinghe-Mudalige \\ U.K. ${ }^{2 *}$, Udugama J.M.M. ${ }^{2}$, Ikram S.M.M. ${ }^{3}$, Weerasooriya L. ${ }^{2}$ and Wijerathne B. ${ }^{4}$ \\ ${ }^{I}$ Department of Horticulture and Landscape Gardening, Faculty of Agriculture and Plantation \\ Management, Wayamba University of Sri Lanka, Makandura, Gonawila (NWP), Sri Lanka \\ ${ }^{2}$ Department of Agribusiness Management, Faculty of Agriculture and Plantation \\ Management, Wayamba University of Sri Lanka, Makandura, Gonawila (NWP), Sri Lanka \\ ${ }^{3}$ Nielsen Lanka Company (Pvt.) Ltd, Colombo 08, Sri Lanka \\ ${ }^{4}$ Provincial Department of Agriculture (North Western Province), Dambulla Road, Kurunegala, Sri \\ Lanka \\ *udith@hotmail.com
}

\begin{abstract}
The role of urban agriculture (UA) towards food security and nutrition is probably its most important contribution, followed by its role as a source of income for a substantial number of urban households leading to development of microenterprises, greening of cities and utilisation of urban wastes. However, in the recent past, these aspects have brought urban agriculture into focus of players of the policy and development spheres of Sri Lanka. In light of this, the paper reports the outcome of a research study carried out to develop a production and socio-economic environment to promote urban agriculture within Kurunegala Municipal Council Limits. With the support of the Provincial Department of Agriculture of the North Western Province of Sri Lanka, 30 urban agricultural producers (UAPs) were selected as the cases for in-depth investigation for this purpose from June 2011. Face-to-face discussions supported by structured interview schedules and visits to their farming areas as well as capacity development workshops and provision of microfinance were carried out with the UAPs on regular basis. Primary data were gathered during this period to: (1) assess the needs of UAPs (Need Assessment); (2) recognize their strengths, weaknesses, opportunities and threats to be in UA (SWOT); (3) explore the good agricultural practices in existence, and (4) evaluate the impact of UA on their livelihood (Impact Assessment), in particular. The information gathered were subjected to various qualitative (e.g. N-Vivo) and quantitative (e.g. ranking, means, percentages) data analysis techniques. The outcome of analyses revealed the existence of diversified forms, systems and types of urban agricultural practices. The need assessment suggests that the majority of UAPs wish to gain a better knowledge on new technologies, waste management and animal feed production. The major strengths of UAPs to engage in urban agricultural activities include the personal health benefits, household food security while their knowledge on marketing and banking were cited as major weaknesses. Opportunities for value addition and market orientation among many producers were also observed. Effective means of urban waste management, alternative sources of energy and self production of planting materials were highlighted as good practices while limitations in land and lower prices for products were cited as key constraints. It found that urban agricultural activities exposed UAPs into many new areas of agricultural production and marketing, which have an impact on their lifestyle, health and family environment.
\end{abstract}

Keywords: Kurunegala Municipal Council, Impact assessment, Need assessment, SWOT, Urban agriculture

Proceedings of the International Forestry and Environment Symposium 2013 of the Department of Forestry

and Environmental Science, University of Sri Jayewardenepura, Sri Lanka. 
The authors acknowledge the financial assistance from National Agricultural Research Plan (2012 - 2014) under its competitive grant NARP/11/WUSL/APM/02 to carry out this research. 